\title{
Technology as a Mode and Manifestation of Being: An Assessment of Its Applications
}

\author{
Theodore John Rivers \\ Independent, Forest Hills, USA \\ Email: trivers13@verizon.net
}

Received July 2 $2^{\text {nd }}$, 2013; revised August $2^{\text {nd }}$, 2013; accepted August $10^{\text {th }}, 2013$

\begin{abstract}
Copyright (c) 2013 Theodore John Rivers. This is an open access article distributed under the Creative Commons Attribution License, which permits unrestricted use, distribution, and reproduction in any medium, provided the original work is properly cited.
\end{abstract}

\begin{abstract}
The objective of this paper is to demonstrate how technology's being is revealed through its applications, which is expressive by means of the mode and manifestation of its being. The designation of technology as a mode of being refers to its nature, and the designation of technology as a manifestation of being refers to its activity as proof of technology's being. Both mode and manifestation indicate how the being of technology is applied. Although distinguishable as two aspects of technology, both mode and manifestation are essential to revealing the essence of technology and its interplay with the world. Since human culture has a technological underpinning, the applications of technology not only reveal its metaphysics, but also indicate its importance to human culture. In addition to technology's underlying method, these applications also pertain to the artifacts (or objects) of invention, mathematics, the consciousness of time, writing, alphabetization, science, and society.
\end{abstract}

Keywords: Technology

\section{Introduction}

Technology is expressive of the choices humanity makes. Unless we encounter extraterrestrials that might be similar to us technologically, we can say that technology is primarily associated with humans. This statement is true while knowing that some animals possess a rudimentary technology, such as the building of nests by birds, the constructing of dams by beavers, and the use of simple tools by chimpanzees. Essentially, technology helps to form the basis of human culture, and it is culture, among other factors, that lies at the foundation of human reality. Although the manner by which humans live in the world determines the use of technology, it should be apparent that modern technology is culturally more inclusive than premodern technologies. Collectively, technology is more than occasionally present; it is omnipresent. Technology comes into being because humanity's being becomes, that is, it is by means of becoming that the being of technology is revealed. This revelation indicates that technology is a dependency because it is based on creative ingenuity, but it is also true that humans have willingly made themselves excessively dependent on its being. Although it is not our concern to discuss the moral implications of technology, it should be kept in mind that technology always has moral consequences because it is the result of human choices.

The essence of technology, if it possesses one, is its presence, which is expressive of its involvement in the world. Technology is the embodiment of human creativity that is the result of the upsurge of our ontological freedom. It is embedded in human choices, occupied by the decisions humanity makes, and committed to the means intended for its projected ends. Embeddedness, occupation, and commitment reveal technology's presence that is a description of a process that is all-consuming. Technology signifies a plan or inducement toward a course of action. It would be a simple step to go from this thought to the realization of the nearly endless applications of technology throughout time. Although the past is always a victim of interpretation, any hermeneutical attempt of it should be guided by the pursuit of truth unaffected by emotion or deception. Humanity's alignment with technology should be sufficient to continue its presence and its impact.

When expressed within this context, technology's importance is self-evident. It is revealed in many ways, beginning with the nature of conceptualization and its relationship to truth. Because human reality is involved with the act of the becoming of being, the latter is the way in which technology makes its appearance in the world, that is, the act of becoming is the conduit for the appearance of the being of technology (Olsen, 2009: pp. 40-61). Although the fundamental characteristics of technology have been discussed many times before, suffice it to say that its applications demonstrate its importance at the present time and anticipate its continuation in the future.

Technology is also supported by the formation of concepts and their necessity for human action. Nevertheless, there is no immediate contact with the world unless it is affected by concepts that help with comprehension. As a requirement for everything we do from spatial orientation to numerical calculation, concepts allow us to understand the world because they are part of the essential framework on which comprehension is based. Conceptualization is associated with the mental process that allows humans to function in the world, and the world may be equated with the summation of social relationships (society), or the physical environment (nature). In addition to these two 
distinctions, there is also the single human being, that is, the self, from which individuality and self-consciousness are derived (Fodor, 1998: pp. 23-29).

As essential as concepts are to humans, they are not extant in the world because they exist only in our heads. A concept is a mental representation from which identity is derived when individual human beings interact with the world or with other individuals. Concepts are played out in the world because the latter is the platform from which action takes place. Therefore, without the world, there would be neither individuals nor concepts. The truth of this relationship should be self-evident, and it supports the idea that concepts and the cognitive development that is associated with them are culturally, not biologically, derived (Donald, 1991: pp. 119-122).

If concepts are related to culture, it should be asked how they are created. And by culture, reference is made not to distinct ethnicities or nationalities, but to human culture in general from which humanity's experiences are based, the experiences that are grounded in the challenges of living in a changeable world, conditioned by the longing to satisfy basic needs, and hounded by life's uncertainties. Human culture by means of evolution has led to the development of concepts, that is, to the development of mental representations that humanity needs for survival. If human understanding reveals a greater complexity, this complexity is imposed on the world. Therefore, mental representation signifies the means by which human culture laid a basis for cognitive development that distinguished humans from other primates.

Because a concept is a mental representation that is derived from perceptions, the latter is not only recognition of mental and physical stimuli, but also an interpretation of them. The integrations of perceptions concern everything. When defined in this way, perceptions become part of a systematic approach to reality because a system concerns the integration of components into a unified whole. Technology plays a key role in helping to satisfy fundamental needs, beginning with methods and organizations and expanding to all manner of applications. Although wants are often confused with needs, both are dependent on technology, which is true even for physiological needs that originate biologically, but are affected technologically.

We should ask how technology becomes the result of conceptualization. Although emanating from the use of ontological freedom that results from a perception of the world, technology is characterized eventually by its applications. Once conceived, technology may be devised, and when devised, it may then be used. Since applications make technology useful, it is creativity that characterizes technology. The manner by which this is done indicates the means by which technology is rendered real in the world.

\section{Technology as a Mode and Manifestation of Being}

The metaphysics of technology is derived from the becoming of being because technology is demonstrative of a process. Although becoming denotes a procedure from which being springs forth, it also denotes the modification of being that already exists. Since becoming, as an expression of being, supplements the being that is, it lies at the threshold of the enlargement of being from which creativity originates. But this process must not be confused with the notion of development or evolution because the latter represents a specific type of be- ing. To develop or evolve usually means to bring something forth from latency, as a way of improving or elaborating something. To come into being means to appear where previously there was no appearance or presence, as a way of springing forth or coming into existence. For example, the materials used in a book already exist in trees for paper or resin for ink, but they do not constitute the being of a book until a book comes into being. Likewise, when a book is destroyed, it will cease to be. The being of a book concerns its presence, and it is through its presence or the projection of its presence that it comes into being.

This process is demonstrated in two ways, that when combined, reveal the nature of technology. First, and more essentially, technology is a mode of being that refers to the nature or the underlying basis to its being. It concerns the means of doing something as a way of positing its existence. Since mode is the medium through which existence appears, it is the way in which technology shows the underlying mechanism of its presence. A mode of being is indicative of the presence of being in general, just as technology's mode of being reveals its presence, that is, its bearing on the world. The second part of this process concerns technology as a manifestation of being. Since manifestation is indicative of the presence of something as proof of it's being, it indicates that the doing of anything, even the doing of technology, is the result of its presence. The mode and manifestation of technology reveal it's being, which is the being that we give it.

Of these two attempts to understand the being of technology, we may conclude that although mode and manifestation are related, one of them may be more fundamental than the other. Since a presence presupposes an essence, we might conclude that a mode of being is antecedent to its manifestation, but it is difficult to separate them. Logically, we might say that if manifestation is an effect of being, then mode is its cause; but metaphysically, they are inseparable. Therefore, for all practical purposes, we should regard the mode and manifestation of the being of technology to be conterminous.

These thoughts are merely preparatory to a discussion of technology's applications. Although other applications could have been selected, the ones that are discussed below are fundamental to human culture.

\section{Method}

An analysis of technology should begin with the concept of method. Although not necessarily progressive, technology's method is developmental. It is no understatement to say that its method expresses more than what is supposedly evident by the nature of any means to its corresponding end. Although means and ends are reciprocal to each other by the very nature of their being, technology's method is much more fundamental because it lies at the core of their relationships. Just as it is inconceivable to think of technology without making reference to process, it is also inconceivable to think of technology without considering its method. Since the latter intensifies the idea of involvement, it is a feature that is fundamental to technology. But it is not redundant to describe method as methodic when the latter signifies a procedural turn of events. If technology's method is not procedural, it cannot be methodic.

Technology's method is not to be confused with methodology. A method is the description of how to do something, but it is not a description of the underlying principles on which it is 
based. Nevertheless, how method is perpetuated indicates a great deal about it. It may be perpetuated by all types of means, by those expressed directly from the context to which they are derived, but technology may also be expressed indirectly by a motley of seemingly lesser means, such as custom, environmental considerations, or economics. Overall, method is most meaningful not with any means, but with a means that is useful, purposeful, and manipulative. We might say that method is a form of perception, but it is not the equivalent of invention. Nevertheless, method is the result or product of invention (Buchler, 1961: pp. 12-13).

Because method is an artifice that presupposes the completion of its tasks, it may be perceived as an agent that allows its tasks to be actualized. Since technology is the effect of its characteristics (notably, rationality, materiality, accumulation, and process), it is also distinguished by a process that accompanies these characteristics and projects them onto the world. Technology's method is twofold: it is a characteristic of technology, and the medium or conveyance of technology itself. If this condition were not true, then technology would not be linked to processes, procedures, and all manner of organization.

An understanding of method in general and its relationship to technology in particular must not be confused with the idea that technology is little more than a matrix or framework, which is proposed by Heidegger as the principle feature of technology (Heidegger, 1977: pp. 11-16, 25-33) ${ }^{1}$. We should emphasize that technology is multilayered, made up of several interdependent characteristics, none of which is more important than another. Nevertheless, technology's method is variable because the circumstances that help to define it are not static, but subject to change. Although circumstances may appear that could lead to new methods, essentially method concerns the improvement of those procedures that already exist. It is repeatable, but not necessarily predictable.

Because technology's method is associated with its essential characteristics, one type may serve as a paradigm for others, but technology does not innately possess any method. If a paradigm is a pattern in the sense of a composite of features or a representative sample that is based on concepts or practices that depicts a way or manner of doing something, even if this is a

\footnotetext{
${ }^{1}$ According to Heidegger, technology is a mode or manner of revealing truth in which something unknown, such as an object or technique, is brought forth into the world, or to use Heidegger's terminology of this revelation: a "challenging, setting-upon revealing". Because technology is associated with truth, it is hidden (to use an ancient Greek concept) and must be revealed through human ingenuity. Therefore, technology is situated somewhere, waiting to be discovered by humans. But Heidegger's interpretation ignores non-being, the description for those things that do not exist. Does technology reside somewhere waiting to be revealed by human ingenuity, or does it not exist at all until invented by humans? An answer to this question is fundamental to an understanding of technology. Heidegger's interpretation makes humans important, but in a subordinate role. More importantly, Heidegger ignores the becoming of being in relationship to technology. Since becoming concerns a process for the realization of being, as discussed in Aristotle, Metaphysics, Bk. II, 2 (994a34-994b2), this process is never complete. Even when inhibited or isolated, technology should continue indefinitely into the future.

Heidegger also contends that we are provoked by technology, and implies that as a result, we are determined by it. Behind this understanding, Heidegger identifies a framework (Gestell in German) that compels humans to respond to technology. It is this framework that makes technology compelling, but this interpretation leaves little room for human responsibility. Heidegger's interpretation of Gestell should not be equated with method because although technology acquires a method, the latter is only one feature of technology's application.
}

way of perceiving reality, then a paradigm is a method. It is a structure around which reality revolves at a particular time and place and from which rules may be derived (Kuhn, 1996: pp. 42-44).

Similarly, method is not a model because a model serves merely as a representation of something, as a plastic miniature can represent a model of an airplane. Although method may be explained as a conceptual model, this relationship is true only in so far that there is an underlying reality to method. Otherwise, a conceptual model would exist theoretically, but not actually. Therefore, we should conclude that method presupposes some type of practical application, since it constitutes more than a mental construction. When method becomes standardized, it is standardization that allows us to speak of the completion of tasks. It is similar to the function of society, in which its individual parts, when applied, are integrated into a whole because society in general manifests a particular conception of reality. In its affiliation with technology, method reveals the effectiveness of its being. It is for this reason that the indefinite article "a" is not used with the noun "method" to fix its identity. Thus, we may speak of method, but not a method because the identity of technology's method is not known.

And it is through effectiveness by which method is most meaningful. Wherever we look, we are likely to discover a heartfelt means by which technology is put into effect. Indeed, what would be the effect of tools, devices, machines, and products, without some manner in which they have an influence on the world? And the same may be said of techniques, which are subordinate parts of method, that is, specialized approaches to completing something. Although these technological effects could be used in ways different from their original intent, nevertheless, they were invented for specific goals, as a chisel was invented to chip and form rock, or the sport of golf was developed based on the mastery of techniques with different clubs.

\section{Artifacts as Tools, Devices, Machines, and Products}

An analysis of technology's applications must also emphasize its material artifacts, which began with the first tools. Given that the first tools were most likely unaltered stones utilized by hominids, all other technologies, except for a few that are genuinely original, are directly related to their predecessors. Anything that humans have produced also incorporates some type of technique, such as the technique of cultivating plants, or making clay pots, or extracting metal from ores. And when anything is made, techniques are created, beginning with a simple procedure and evolving into more elaborate ones. Technology is based on the accumulation of its results, evolving from the simplest to the more complex (Arthur, 2009). Because technology is made up of several interrelated characteristics that are used, elaborated, extended, modified, or reinvented, it is the result of many factors, only one of which is accumulation. And since accumulation is related to technological efficiency, the latter indicates that the best possible means should be selected when completing a task. If no means exist, then one can be invented.

A distinction should also be noted about the artifacts of technology, particularly, the definition of a tool as a device, and a device as a tool. We should not be confused about the reciprocal relationship because tools and devices since both are universal descriptions of the artifacts of technology. A device is an invention designed for a specific purpose, but this definition is 
applicable as well to tools that are devices that work manually or mechanically. Therefore, tools and devices may have equivalent descriptions, but the definition of a machine is also relevant in so far that it is a more elaborate device. To say that a machine deals with fixed and movable parts would designate even a shaduf as a machine because it has a fixed weight at one end that is moved to counterweight a basket at the other end to scoop up water for irrigation. If a shaduf is a simple machine, then many other devices associated with antiquity are also, such as the lever, pulley, inclined plane, or wedge (McNeil, 1990: pp. 17-18).

As already noted, technology in large part concerns artifacts of invention, which evolved from the simplest techniques of scavenging for meat from dead animals by hominids and early humans to hunting them with weapons of wood and stone. Eventually, humans become nomads who hunted animals and gathered fruits, nuts, and roots. A comparison of the rudimentary technology, for example, of Paleolithic humans during the Ice Age and our own technology leaves much to be desired, in fact, almost everything. Having no domestic implements except for the needle used to sew animal skins together to make clothes and boots, even lacking the bow and arrow, Paleolithic humans survived because they had fire, and could use it to cook food and stay warm. As primitive as the technology was for Paleolithic humans, the fact that they had technology that aided their existence is proof of their innovative ability as an essential characteristic of their being.

Eventually, the hunter-gatherer became a herder of animals, and later, a cultivator of plants. In addition to food, animals were also used for other purposes: clothing (derived from their skins), transportation, physical power, and protection. Because a settled way of life became the predominant life style for many people and led to civilization, permanent agricultural settlements gave rise to dietary changes whose techniques were included in the so-called Neolithic revolution that began in the fourth millennium BCE. These techniques involved the development of procedures, beginning with the identification of potentially useful plants that could be cultivated, and ending with the preservation of seeds for the next growing season. By trial and error, agriculture entailed the invention of special tools for working the land, and techniques for maximizing the likelihood of successful cultivation.

Similarly, other technologies were also affected, such as the making of clothing (the loom), pottery (the potter's wheel), and metal utensils and weapons (metallurgy). Apart from the use of various minerals found lying on the ground, metallurgy became a specialty because it entails the substitution of one component of metallic ores with another (usually sulfur) through the application of high temperatures, a procedure that took several centuries to perfect.

The tools and machines that were developed in prehistory and antiquity, and that served as an introduction to the sophisticated counterparts of later generations include all major categories of technological innovation. From the hoe to the plow, the water mill to the windmill, the abacus to the computer, the water clock (clepsydra) to the mechanical clock, the telegraph to the telephone, the cannon to the automobile, the motor to the generator, the technologies of the past have influenced the technologies of later generations. It is impossible to think of technology without making reference to its artifacts, as enumerated above, and its artifacts are expressive of the being of technology, a revelation of humanity's continuous application of the need to assist human existence by modifying nature. And the effects of this need are everywhere and in every aspect of our lives. Because inventive ability is emphasized through tools and machines that indicate how society acts and reacts, invention is indicative of the being of technology as a force in history. When applied, invention is transformed into innovation. And the accumulation of innovations represents a process of ingenuity, exerting an influence on humanity much greater than its original purpose.

\section{Mathematics}

Formal schooling usually includes an introduction to mathematics. Even when this introduction is limited to arithmetic, it is accompanied by the idea that numbers and mathematical functions are natural, that is, they are not fabricated. Since the study of mathematics concerns the idea that numbers in particular and mathematical entities in general exist independently of human beings, this idea has little significance for anyone who is not concerned about the origin of mathematics, but much significance for anyone who thinks that numbers are a valid topic for reflection. Hence, it is to philosophy of mathematics where the notion of mathematical concepts is pertinent. It is within this context that mathematics is perceived either to exist apart from human reality or remains dependent on it, that is, mathematics is either innate within itself or created.

Of course, numbers would have no bearing if they could not be understood. Some animals, such as pigeons and chimpanzees, may be assumed to possess a rudimentary numerical ability (Honig, 1993: p. 62; Thompson, 1995: pp. 199-200), but the latter must be differentiated from the symbolization associated with numbers. We may conclude, to which science gives support, that numbers reflect a mental identification that is the result of the perception of physical objects. They are not descriptions of what are naturally in the world, but enumerations of how objects are perceived (Russell, 1956: p. 529). A number is an idea with its corresponding meaning of enumeration that we impose on the world. Indeed, we may find many things in the world, but nowhere will we find numbers. Although constituting an important part of human reality, numbers are real as concepts, but not real as things (Carnap, 1983: p. 42). To write a number on a piece of paper does not confer reality. A number is a concept represented by a numeral, as the Arabic numeral 4 (or the Roman numeral IV) stands for the number that immediately follows the numeral 3 (or III) in a progression of symbols. Despite being used in association with objects, numbers lack factual content and are not verifiable empirically, since they are merely mental representations of things.

Arithmetic, as the simplest area of mathematics, is an extension of object identification. Like many other things we do, arithmetic is a reflection of everydayness, but it is also a reflection of the need to modify its conditions. Therefore, every person should have a fundamental understanding of mathematics because of the human capability of counting and identifying objects. It is from object identification that humans are able to add and subtract, multiply and divide (Lakoff \& Núñez, 2000: pp. 77-78). All other areas of mathematics from algebra and geometry to trigonometry and calculus are artificialities. They are expressions of human consciousness imposed on the being of the world.

Why would we need higher forms of mathematics? Although algebra originated in antiquity, it later concerned the substitu- 
tion of letters for numbers in arithmetical equations, a substitution that was expanded in the sixteenth century by the French mathematician François Viète (Hazewinkel, 1988: p. 73). We should ask why there would be a need for a branch of mathematics that seems to make the latter deliberately complex. Although algebra was invented as a tool to discover unknown quantities in mathematical equations, the use of letters for numbers attempted to uncover universal formulas when applicable to similar examples.

As is widely known, geometry concerns uncovering the mathematical relationships between points, lines, angles, and solids. We can refer to the first known historical reference to geometry in The Histories, written by Herodotus in the fifth century BCE that describes the desire to measure land in Egypt after the annual flooding of the Nile (Herodotus, 1998: pp. 135-136). The practicality of geometry is evident as a means of reassessing land measurements that in turn is applied to many other occasions when referring to space and distance. Geometry became a simple tool for the practical application of mathematics.

Similarly, trigonometry concerns the mathematical relationships of the sides and angles of triangles. It was developed, most likely, as an extension of geometry, particularly, for the use of surveying land in the determination of boundaries, and the construction of roads and buildings. It was developed as an applied science, and fulfilled a rudimentary step in the study of mathematical functions when no quantitative value is known, which mathematically is described as a variable.

The branch of mathematics that expands trigonometry and that deals with the differentiation and integration of functions of one or more variables is known as calculus. It concerns analyzing one set of numbers in relationship to another. Differential calculus concerns finding the rate of change between these two sets. The opposite operation to differentiation is integral calculus in which change as a factor is already known, but the result of change is not. As introduced independently by Isaac Newton and Gottfried Wilhelm von Leibniz in the seventeenth century, differential and integral calculus are essential to understanding the movement of objects in space. Apart from the calculation of gravity, the invention of calculus had a technical application because ballistics (the study of missiles and trajectories) was directly related to astronomy. Once the science of ballistics was developed, aeronautics was rendered possible as well.

We must conclude that if arithmetic is innately conceptual, then all other branches of mathematics must be extensions of elementary mathematics. Because of the way these extensions are utilized, they may be described as technological modifications of basic mathematics, since they are organizational approaches to reality. They are used, for example, to construct buildings, to measure canals for irrigation, to erect aqueducts or roads, to calculate the trajectory of satellites into the atmosphere, to create all types of devices, to formulate images in pixels - all of which, whether ancient or modern, are the result of applied mathematics, an application that would be unnecessary or undesirable in a society in which the being of technology has lesser importance. As we said above, mathematics is the technological effect of a numbering system derived from the identification of objects. Although mathematics evolved into the systematic study of the symbolic relationship between quantities, it remains at heart the result of a self-expression that has been technologized into a highly skilled scientific discipline.
It is a revelation of how the world, itself the result of human activity, can be explained as an extension of humanity's mental positing of the world. Because mathematics is an example of the workings of human ingenuity, it is one way in which humanity gives meaning to the world.

\section{Writing and Alphabetization}

Whether humans can speak or are mute, and they are not paralyzed, they all communicate in some way, but the most useful form of communication is writing. In non-literate cultures in which traditions are past down orally to succeeding generations, the inability to commit traditions to writing, or to record new discoveries, relegate their cultures to an inferior position. Nevertheless, speech offers only a partial conception of language, which is supplemented by the practicality of writing.

But writing is dependent on texts. Is a text defined solely by the fact that it is written down, or does it transcend its medium? Materially, a text is commonly defined by a clay tablet, stone stele, papyrus, vellum, paper, or electronic transmission that it depends on, but a physically related medium portrays a text (even when electronically devised) from only one perspective. In a sense, texts are transcendent, although they are tied to their medium, as they are tied historically to the age in which they are produced ${ }^{2}$. Therein lies a major difference between literate and non-literate cultures.

Naturally, a textual transcendence is dependent on future generations. Although countless original texts have been lost in the past, they may continue to exert an influence because copies had been produced, such as those texts laboriously copied by monks in European monasteries during the Middle Ages, or reprinted for modern use by the printing press. Since texts presuppose the existence of writing, conversely we can say that writing presupposes the existence of texts, or at least the assumption that somehow they must exist. If writing and texts are associated with literacy, then their absence is associated with illiteracy (Stock, 1983: pp. 3-4, 8).One can be taught to read and write without a dependency on texts, but it may be presupposed that reading and writing are somehow related to them. We should also ask if texts exert an influence on our collective memory, but it is not our task to assess whether or not this influence is long lasting. It is possible that a tradition, idea, or remembrance may be lost because conditions, either deliberate or accidental, may have been set in place that have allowed for forgetfulness.

These thoughts, however, are merely preparatory to an understanding of writing. Although language is phonetic because it depends on sounds as a means of communication, writing also intensifies it. This relationship is evident when we reflect that language is based on distinct sounds, each represented by a sign, which when written may be preserved indefinitely. Language, of course, is more than just sounds because it is derived from conceptualizations that are the result of human interaction with the world. Despite being adversely criticized for attributing signs as the only requirement for language, Ferdinand de Saussure in the early twentieth century concluded that language begins with representation of signs through concepts (Saussure,

\footnotetext{
${ }^{2}$ Texts bring to mind their importance to religions, from the Vedas to the Quran, from the Old Testament to the New Testament of the Bible. Even for Martin Luther, faith in the Bible guaranteed salvation, but this conclusion presupposed the technology of writing.
} 
1983: pp. 28-29, 98, 146).

Because a written language presupposes the existence of signs, either logographic, pictographic, or alphabetic, signs would be non-existent without a written language. Although it may be concluded that writing began in Mesopotamia in the late fourth millennium BCE, no alphabet existed at that time. The development of writing represents a slow, laborious process, and reflects the increasingly complex nature of human culture, especially, as a result of urbanization. The earliest writing emphasized consonants only, although the sound of vowels was included in the pronunciation of words. Because writing originally addressed practical matters that served as descriptions of commodities used in trade or donations made to local temples, it heightened the preservation of data without relying on memory. In Mesopotamia, cuneiform fulfilled this function, and in Egypt, hieroglyphics. Writing also acquired importance because it became the means that distinguished history from prehistory. And by writing we are not referring to casual markings or signs on objects for a specific purpose, but a system of preservation of cultural significance for a general purpose. Essentially, writing denotes a system of communication, not a conglomerate of isolated signs.

The simplification of writing was accompanied by the invention of the alphabet. Although the Phoenicians may be attributed with modifying the alphabet, they were not its innovators. The alphabet in a most rudimentary form is attributed to the Canaanites when they lived and worked in the Sinai Peninsula, although assigning their writing to a precise date is difficult. This earliest alphabet evolved as a simplification of hieroglyphics, which itself is a highly sophisticated and stylized system of pictographs that originally represent an object or a sound (Gardiner, 1957: p. 8). The alphabet is based on letters, not pictures, and above all, it is not based on objects. In this sense, writing is not natural, but artificial. The alphabet gave rise to letters as representations of sounds. It is an example not only of a technological application that transcends the natural world, but it is also an indication of technological civilization itself.

The alphabet associated with the Sinai Peninsula and later with Palestine, respectively known as Proto-Sinaitic and ProtoCanaanite, must be distinguished from a cuneiform alphabet that developed at Ugarit in western Syria in the fourteenth or thirteenth century BCE (Puech, 1986: pp. 197-198). The ProtoSinaitic alphabet is considered to have been developed between the seventeenth or sixteenth centuries BCE (Naveh, 1987: pp. 26-27). It later influenced the alphabets associated with the Phoenicians, Greeks, and Romans. Although the introduction of letters for vowels is accredited to the Greeks, the Phoenician alphabet, emphasizing consonants only, had an influence on the Aramaic alphabet from which Hebrew and Arabic developed.

Writing is a way of recording information so that it may be preserved. It is a way in which other people, who may or may not be directly involved in writing themselves, may benefit from it. Because writing appeals to a much larger audience than the audience immediately intended by authors of particular works, it has an influence far greater than many other human endeavors, which is now augmented by the internet. Even when attempting to understand an ancient people, the preservation and decipherment of their writing give insights into their culture. Although these thoughts may explain why writing is important, they do not explain why alphabetization was invented. Actually, we should not ask why any one alphabet was invented.
Instead, we should ask why alphabets in general, some earlier and some later, were invented.

Nevertheless, there have been several explanations for the origin of the alphabet, such as an attempt to preserve a people's literature, or an effort to leave a mark of one's presence, or an intensification of writing that serves as a substitution for speech, or a proposal to develop a national script, but none of these explanations seem to address the fundamental reason why an alphabet was invented. Although these explanations hold some practicality, they do not seem to reveal its underlying necessity. Of course, after its invention, the alphabet was adopted by many cultures for different purposes over vast expanses of time. The fact that there were the proto-Sinaitic and cuneiform alphabets should lead to the conclusion that alphabets facilitate and simplify the technology of writing, and illustrate their importance to human culture (Coe \& Van Stone, 2001: p. 20) ${ }^{3}$. More important than any one alphabetic script is the idea of alphabetization itself as the means for the increased importance of the technology of writing that communicates with a present generation and preserves information for future generations.

Writing is a learned experience that promotes factual information for practical purposes, which then may be applied to other endeavors, such as literature. Although many literary works, such as the Epic of Gilgamesh, the Iliad and the Odyssey, or Beowulf were originally oral, they were subsequently committed to writing, which increased their importance to their respective cultures. The same phenomenon is also applicable to the legal customs or laws of a primitive people. Writing is the means by which the influence of the past may be extended into the future. Therefore, the past acquired new meanings when preserved in writing because writing allowed memory to be projected indefinitely into the future. Like mathematics, the invention of writing has lent itself to humanity's innovative accumulation and indicates that the metaphysics of technology is demonstrative of a process of becoming.

\section{Science}

The definition of science has changed over the ages, but for the present age, science is far more specialized in its analysis of reality when compared with the more general applications of science in the past. Although many topics that qualified as science in antiquity would be categorized in the modern age as pseudoscience, it is not our intention to pass judgment on what legitimately was science in a former age. Nevertheless, regardless of the age in which it appears, we should ask how science is related to technology. Although there may be some confusion about the influence of science on technology, there should be no confusion about the influence of technology on science. Science and technology evolved with distinct objectives. Science concerns an understanding of the manner in which knowledge about reality is acquired, no matter how far reaching that may be, but technology concerns the practical applications of that knowledge. As a result, a distinction evolved between theory and practice. But as technology invaded the exclusive areas of science, the latter lost its purely theoretical basis and was rendered technical instead. We should speak of science's technologization more than technology's scientification. Since technology dominates everything we do, it could just as easily

\footnotetext{
${ }^{3}$ The Landa or Mayan alphabet is not an authentic alphabet, but an artificality created by Diego da Landa, a sixteenth century Catholic bishop, who wanted to convert the Maya to Christianity.
} 
function without regard for usefulness. This is to say that method takes precedence over practicality (Habermas, 1974: pp. 253-256). In this sense, practicality loses its importance because the bulk of our emphasis revolves around technology's performance to the exclusion of everything else which is manifested through technology's prolific ubiquity.

In some way, science has always been associated with technology, at least in so far as technical applications are concerned. But in the modern age, technological apparatus, instruments, devices, and procedures commandeer science. No longer independent and no longer superior, science has been rendered subordinate to technology, since the triumphs of science are rendered possible only because of benefits made available by technology. For example, chemistry has advanced considerably because of the refinement of laboratory equipment, and without it, chemistry would have progressed little since the time of Lavoisier. If science has become more technical, its technicality is attributable to its technologization, which would seem to be true in both western and non-Western cultures (McGinn, 1990: pp. 22-27).

The displacement of science by technology, or at least the accelerated influence of technology on science, occurred with greater intensity in the nineteenth century when the industrial revolution took place (Pollard, 1981: pp. 85-87, 142-148). At that time, the techniques of technology were greatly aligned with the methods of science. No longer could science proceed without the benefit of technology, although technology does benefit from the discoveries of science that, for example, allow for the invention of better tools and machines. The alignment of science with technology occurred by a gradual process that resulted in the manifested presence of technology in all aspects and in all places of the world. Consequently, we may describe the technologization of society more as a process of degree rather than kind.

The advancement of modern technology, and therefore its relationship with science, is essentially twofold. First, technology has benefited from the past because of its historic evolution, to which initially it made a minor contribution, but from which eventually it was the principal beneficiary. And this past is attributed to the European Middle Ages, which gave to technology its dynamic forward directedness that was acquired from Christianity and a Christian culture (Benz, 1966: pp. 121-142). Second, the method of science had changed at the end of the Middle Ages that initiated not only a new way of looking at reality, that is, a new science, but also a new way of applying this knowledge that facilitated a new technology. This new method formed the basis of the scientific revolution, in which technology was "implied as a possibility in the metaphysics” of the new science (Jonas, 1974: pp. 47-48).

But more than its implication and its Christian underpinning, technology came to represent metaphysics itself. It surpassed the science that resulted from the scientific revolution and replaced the metaphysics of the Middle Ages, that is, technology superseded Christianity as the foundation of the metaphysics of Western civilization. Ultimately, technology became expressive of the metaphysics of the world at large. More than being in the world, technology is expressive of the being of the world. It owes a debt, in part, to the past for the impetus in accomplishing this goal. To express these thoughts in other words, we might say that humanity's being is reflected unto technology. It demonstrates that technology's mode of being is revealed as a manifestation of ourselves.

\section{Time-Consciousness}

Because of sundials, water clocks, and mechanical clocks (and by extension, quartz digital clocks and watches), time reckoning has evolved as a consequence of time's computation. But more than time reckoning, it is time-consciousness that concerns us. In fact, time-consciousness-itself an effect of technology - is rendered possible primarily because of the reckoning of time. Of these three different inventions described above, it was the mechanical clock, conceived and developed in the late Middle Ages, that led to time's mechanization, in which time is not only compartmentalized into smaller and smaller units, but also rendered into a commodity that could be regulated, manipulated, and projected. Above all, time-consciousness exerts an influence on daily life as to transform completely an undefined understanding of time into a motif that penetrates everything. If time was not an important feature of the human psyche before the invention of the mechanical clock, it certainly has become one since its invention, whose ticking manifests a presence of time's fragmentation. Everything from birth to death is now adjusted or tempered by time-consciousness. The vehicle for making money or pursuing pleasure, for devotion to one's family or the pursuit of idleness occurs by means of the consciousness of time, which inevitably is followed at some point by the fear of wasting it. Consciousness of the passing of time dominates all aspects of life. Because the telling of time in many languages relates to a description of time derived from the clock, the latter has acquired a meaning far beyond its original intent (Rivers, 2000: pp. 225-226).

The augmentation of time by means of technology is not to be confused with natural cycles or so-called economic cycles representative of the effects of prosperity (or its lack) because they do not obliterate technology's progressive momentum. The fact that there is a cycle of anything does not preclude the linearity of time, which is the result of the Christian conception of time (and its biblical background) that helped with technological progress. Likewise, the difference between time internally experienced, which is ontological (a natural metaphysical phenomenon), and time externally given, which is artificial (an unnatural metaphysical phenomenon), is exaggerated by technology. This exaggeration plays a part in the distortion between the future and its absorption by the present, so that the possibility of the future seems to be consumed by an ever-present present, a characteristic that is attributable to the clock. Consequently, the perception of time is variable, ranging from mandatory obligations to free time, from an emphasis of time as a quality to its emphasis as a quantity. In fact, time acquires a power hereto non-existent because its quantity enables it to become the means of accomplishing anything (Blumenberg, 1986: p. 223).

Nevertheless, how would society be made aware of time reckoning if there was no way to be informed of it, if there was no clock in the town square, or if there were no watches? If time were not tied to specific hours of the day, what use is timeconsciousness? Since the invention of the mechanical clock, which itself had a slow and localized influence in medieval monasteries before it had an influence on society in general, time-consciousness took much time to be perfected. Likewise, other changes in the past have also taken considerable time, even centuries, to have an impact, such as the use of the wheel, 
domestication of plants and animals, or writing. Even as late as the eighteenth century, time-consciousness had no influence on people who had little need for it (Landes, 1983: pp. 227-228).

Time-consciousness is not inherent in the being of being human, but it is a mode or manner of an awareness of temporality as a characteristic of being. Time-consciousness is a technological artificiality, but temporality is an ontological reality. There is no being without time, and no time without being. Since temporality is a characteristic of being, it may be supplemented by time-consciousness that is artificially induced by technology. Whether or not human reality has benefited by this relationship is not the issue. Calculating the time of day by noticing the rising and setting of the sun, or by reading the stars after the sun has set gave the first glimpses of the passing of time that goes back to time immemorial; but these simple happenings lacked the precision of time-consciousness with its positive or negative connotations. Like so many other happenings, once a threshold has been crossed, it is impossible and anachronistic to go back. As in other endeavors, technology is the result of an accumulative process. It is based on the choices of the past that help to set the conditions of the future.

How much has time-consciousness changed human culture? How much has it altered forever the way the world is perceived? If time-consciousness can be ignored and the world can continue without time's overbearingness, then time-consciousness is irrelevant, but the world has changed because it has been compartmentalized. Even when time awareness is rejected and people move to a remote island somewhere, this desire is chosen most likely because they are conscious of time. This rejection of time-consciousness is the immediate result of the cognizance of time's ubiquitous presence (Griffiths, 1999: pp. 1115).

\section{Society}

Human society is a social structure definable by networks of interaction among its members who generally demonstrate a willingness to work cooperatively, and who often show a sense of fairness, or at least mutuality. Although society may also refer to chimpanzees, baboons, bees, and ants, for our purposes we will limit the use of this term to humans only. Because the societal relationships manifested by these other animals are the result of evolution, the benefits of cooperation among members of one's own species, human or non-human, should outweigh any advantages supportive of individuality. As far as humans are concerned, the social structure associated with cooperation originates between two or more people, and most commonly within a family, even if the latter consists of a husband and wife cohabiting without children.

Related to the idea of association is the notion that society denotes a type of organization, and it is organization that is particularly important. How an individual reacts to another lays the basis for society, whether expressive of identity that is based on ethnicity, culture, social solidarity, or patterns of authority. Like the system introduced into Chinese society by Confucius whose goal was the maintenance of stability in an uncertain time, society in general deals with relationships between and among individuals, families, communities, countries, cultures, and by extension, civilizations.

One should ask if social mechanisms associated with society are derived from interactions between people that require more than one person, or derived from the human brain that is indi- vidually based and not initially tied to other people. Regardless of its derivation, it is the interaction between people that is the basis for society because if humanity were reduced to only one individual, there would be no need for (and no benefit derived from) other people. Society does not exist when humanity is reduced to a sole survivor.

Indeed, what need would there be for society unless it achieved something that individuals could not achieve alone. In some sense, when compared to politics, we may say that society is similar to a confederal system in which a central government has the power to do something that individual state governments cannot do efficiently for themselves and from which central governments derive their power. Similarly, if the purpose of society is the attainment of social goals, these goals are variable. They would differ among societies, but they would also differ within them, as if each enclave within a community or country denotes a distinct society with noticeable differences, such as the associations of a crime family, a religious community, an ethnic neighborhood, personal affiliations within a profession, or any subdivision of a culture. Societies regulate some type of social order, but they become more complex when they reveal elaborate patterns of control. Nevertheless, we are not concerned with the alleged stages of social evolution that impact the development of society, but with the importance of society in general.

Society comes into existence from the interaction of at least two people, and therefore, it is as old as humanity itself. The question for us to ask, therefore, is self-evident: If society is natural, to what extent is it influenced by technology? Or we may rephrase the question: How have different technologies given rise to different societies? Since culture determines what makes us human, we are defined by willful human choices. It is a common conclusion within anthropology that humanity is defined culturally, not biologically. It is this distinction that separates humans from other life forms. If society could be defined solely by biology, then it would hardly be subject to technology.

Anthropologically, culture may be defined as a configuration of the natural order. Because the relationship of the natural order with an alleged "human nature" is determined by biology, we must conclude that human nature is a distortion because it supposedly is a description of qualities that all humans share. An accurate definition of human nature should include physiological traits because humans are mammals. Non-physiological traits that would more accurately define the nature of humans are traditionally excluded because these traits are variable. It is variability that indicates that culture, not biology, is what defines us. Therefore, the designation of human nature from any other perspective as a definition of culture is a misnomer.

It should be apparent that society helped cognitive development, and it is fundamental to the promotion of social behavior. Given that human society is often compared with simian societies, it is more complex than the latter and entails greater organization. Any elaborate organization implies some type of technology. When referring to society, its structure reveals that its individual components are combined in particular ways that form integrated wholes. Society concerns the means by which individuals are incorporated into a framework. The process in which this integration takes place is technological. But societies are not passive because they develop through conflict, that is, through deliberate actions that shape cooperation and form complex institutions. One type of conflict concerns warfare, 
and another type concerns trade. Therefore, conflict may have negative and/or positive consequences, both of which are affected by technology.

It may be impossible to uncover the conditions that led to the first human societies, but the transition from pre-human (or hominid) to human society most likely included the development of spoken language because the latter is paramount for cooperation, without which well-developed social relationships would be impossible. Regardless how long it may have taken to develop language with all its complexities, changes in kinship and even the development of myth may have been important for its evolution (Barnard, 2011: pp. 92-93, 109). The social cooperation that was needed for hunting and gathering helped in the development of society, both of which evolved with an increase in brain size, and all of which facilitated the development of language. Experiences evolved into traditions that could be perfected, and traditions evolved into societies that could be expanded. As a result, cultural evolution was the beneficiary of these events.

Since spoken language entails the designation of sounds for distinct entities, early humans must have developed words as a way of understanding the world. Nevertheless, we should be mindful that to look for the origins of anything is really to seek the causes that answer all our questions. Such a quest is both beyond our reach and highly suspect (Bloch, 1953: pp. 29-30). The earliest tools, which were unmodified stones, were used by hominids, but the skills required for the flaking and chipping of them came much later and probably were associated with the development of speech. Thus, technology, language, and cooperation (or altruism) are associated with human society and played a part is its development (Hurford, 2007: pp. 268-271).

It should go without saying that technology is a human phenomenon. Although one person can invent a technology, any social application it may acquire must be distinguished from its invention. This idea concerns the truth that technology is more than a human phenomenon; it is also a social one. For example, was the wheel invented for the benefit of one person who had wares to transport, or did several people contribute to its invention for their mutual benefit, such as its use for ceremonial reasons? It is possible that the wheel could have been invented for either purpose, but it was only after it was applied among many people that it acquired social significance, that is, acquired an importance to society. And we should also consider the environmental conditions that may or may not have allowed the wheel to be useful (Basalla, 1988: pp. 9-10). Although individuals precede society, society is followed by humanity. And by humanity we mean the qualities of being human, which takes place when individuals cooperate and become integrated parts of a group and promote its well-being. It is at this point where technology achieves its greatest impact, that is, when inventions appear, when they are modified, even when they are abandoned.

These thoughts lead to another. If society is a type of social organization, then it is a type of method. But we do not have to ask where this organization originates. It is apparent that we create it because societies are variable based on the cultural conditions from which they evolve. Although societies must address the human condition to which all people are subject in the satisfaction of basic needs, how societies deal with these conditions vary widely. An introduction to cultural anthropology reveals the infinite variety of human societies. It indicates that society, for example, is characterized by the way in which it uses technology in maintaining life, in protection from harm, in food production, in education, in planning for the future. These examples are expressions of social mechanisms that bind people together and promote solidarity of the entirety of human life. They indicate that technology's presence is expressive of a fundamental truth about the nature of society, a truth that indicates that the social structure of society is supported and promoted by means of technology, in fact in everything we doin our lives. Without it, society would be represented by a disjointed assemblage of human beings struggling to maintain daily existence. Metaphysically, we may say that society, as the embodiment of human reality, reveals its own being, that is, the being of the world, by means of technology.

\section{Conclusion}

Technology is the result of human ingenuity, originating from ontological freedom, influenced by conceptualization, and given actuality through the manipulation of the world. Together, these factors help to describe the essence of technology. As we said above, technology's involvement reveals its essence. Its interaction with the world is embedded in our choices, occupied by our decisions, and committed to the means that are projected to their ends. Since the essence of technology is founded upon its presence, the latter is fundamental to its being. Technology is made real initially through praxis, since praxis is how technology's engagement is played out. For example, writing is a mode of technology. It maintains a presence through its exercise of symbolization, but writing in itself is not essential to technology. Writing may be important for communication, society, and human progress, but it is not fundamental to technology's essence. The technological importance of writing does not concern what is written, but rather the process or manner of writing. It concerns the symbolization of signs and letters, that is, the substitution of written words for things. Whether these words are written in Arabic, Urdu, or Greek is incidental. It is the idea of writing, rather than its form, that makes writing important. And technology's being is applicable to all the categories we have discussed above. Therefore, the being of technology, regardless of the form it takes, concerns its overriding reality, as if it possesses an aura of some distinct quality or breadth of vision. Although any being, that is, any entity, possesses potentiality because being denotes existence, nevertheless, potentiality may not be actualized. It should be assumed, however, that technology's being would have an impact on the world by its mere presence, which is expressed through its applications.

As we said above, the being of technology is expressed through its applications, which begins with the nature of conceptualization and its relationship to truth. Once technology is conceptualized, it may be devised and used. Applications are the means by which technology is made evident, from the first tool to the last, from a simple procedure to the most complex, from a particularized technique to a generalized method. Because it participates in human activity, technology is one link between thought and action, that is, between thinking about the world and creating it. It manifests the completion of tasks when its designated means attain their ends. Like art or literature, technology is a phenomenon that transforms humans and changes the world. It is the means by which humans express their being, that is, technology is the way in which humans reveal their being to the world. And what is the world if not our 


\section{T. J. RIVERS}

inheritance of the cultural conditions of the past that result from innovative accumulation (Ogburn, 1964: pp. 24-27).

\section{REFERENCES}

Arthur, W. B. (2009). The nature of technology: What it is and how it evolves. New York: Free Press.

Barnard, A. (2011). Social anthropology and human origins. Cambridge: Cambridge University Press.

doi:10.1017/CBO9780511974502

Basalla, G. (1988). The evolution of technology. Cambridge: Cambridge University Press.

Benz, E. (1966). Evolution and Christian hope: Man's concept of the future from the early fathers to Teilhard de Chardin. Frank, H. G. (Trans.). Garden City: Doubleday.

Bloch, M. (1953). The historian's craft. Putnam, P. (Trans.). New York: Knopf.

Blumenberg, H. (1986). Lebenszeit und weltzeit. Frankfurt: Suhrkamp.

Buchler, J. (1961). The concept of method. New York: Columbia University Press.

Carnap, R. (1983). The logicist foundations of mathematics. In P. Benacerraf, \& H. Putnam (Eds.), Philosophy of mathematics: Selected readings (2nd ed., pp. 41-52). Cambridge: Cambridge University Press.

Coe, M. D., \& Van Stone, M. (2001). Reading the Maya glyphs. New York: Thames \& Hudson.

de Saussure, F. (1983). Course in general linguistics. Bally, C., \& Sechehaye, A. (Eds.) with collaboration of Riedlinger, A., Harris, R. (Trans.). London: Duckworth.

Donald, M. (1991). Origins of the modern mind: Three stages in the evolution of culture and cognition. Cambridge, MA: Harvard University Press.

Fodor, J. A. (1998). Concepts: Where cognitive science went wrong. Oxford: Clarendon Press.

Gardiner, A. (1957). Egyptian grammar: Being an introduction to the study of hieroglyphs (3rd ed.). Oxford: Oxford University Press.

Griffiths, J. (1999). Pip pip: A sideways look at time. London: Flamingo.

Habermas, J. (1974). Theory and practice (abridged 4th ed.). Viertel, J. (Trans.). Boston: Beacon Press.

Hazewinkel, M. (1988-1994). Encyclopaedia of mathematics. Dordrecht: Reidel.

Heidegger, M. (1977). The question concerning technology and other essays. Lovitt, W. (Trans.). New York: Harper \& Row.

Herodotus. (1998). The histories. Waterfield, R. (Trans.) with an introduction and notes by Dewald, C. Oxford: Oxford University Press.
Honig, W. K. (1993). Numerosity as a dimension of stimulus control. In S. T. Boysen, \& E. J. Capaldi (Eds.), The development of numerical competence: Animal and human models (pp. 61-86). Hillsdale: Erlbaum.

Hurford, J. R. (2007). The origins of meaning: Language in the light of evolution. Oxford: Oxford University Press.

Jonas, H. (1974). Seventeenth century and after: The meaning of scientific and technological revolution. In L. E. Long (Ed.), Philosophical essays: From ancient creed to technological man (pp. 46-82). Englewood Cliffs: Prentice Hall.

Kuhn, T. S. (1996). The structure of scientific revolutions (3rd ed.). Chicago: University of Chicago Press. doi:10.7208/chicago/9780226458106.001.0001

Lakoff, G., \& Núñez, R. E. (2000). Where mathematics comes from: How the embodied mind brings mathematics into being. New York: Basic Books.

Landes, D. S. (1983). Revolution in time: Clocks and the making of the modern world. Cambridge, MA: Belknap Press.

McGinn, R. E. (1990). Science, technology, and society. Englewood Cliffs: Prentice Hall.

McNeil, I. (1990). An encyclopaedia of the history of technology. London: Routledge. doi:10.4324/9780203192115

Naveh, J. (1987). Early history of the alphabet: An introduction to West Semitic epigraphy and palaeography (2nd ed.). Jerusalem: Magnes Press.

Ogburn, W. F. (1964). On culture and social change: Selected papers. Duncan, O. D. (Ed.). Chicago: University of Chicago Press.

Olsen, J. K. B. (2009). Becoming through technology. In J. K. B. Olsen, E. Selinger, \& S. Riis (Eds.), New waves in philosophy of technology. Basingstoke: Palgrave Macmillan.

Pollard, S. (1981). Peaceful conquest: The industrialization of Europe, 1760-1970. Oxford: Oxford University Press.

Puech, É. (1986). Origins de l'alphabet. Revue biblique, 93, 161-213.

Rivers, T. J. (2000). The conception of time and its relationship to technology. Research in Philosophy and Technology, 19, 215-231.

Russell, B. (1956). Definition of number. In J. R. Newman (Ed.), The world of mathematics: A small library of the literature of mathematics from A'h-mose the scribe to Albert Einstein. New York: Simon \& Schuster.

Stock, B. (1983). The implications of literacy: Written language and models of interpretation in the eleventh and twelfth centuries. Princeton: Princeton University Press.

Thompson, R. K. R. (1995). Natural and relational concepts in animals. In H. L. Roitblat, \& J.-A. Meyer (Eds.), Comparative approaches to cognitive science (pp. 175-224). Cambridge, MA: MIT Press. 